\title{
Neutrophil function and diagnosis of pre-leukaemic states
}

\author{
J. B. HoughtoN \\ M.B., M.R.C.P.
}

\author{
Haematology Department, City Hospital, Nottingham
}

\begin{abstract}
Summary
Haemopoietic dysplasia is a condition which often precedes the development of acute non-lymphocytic leukaemia. Before this event, however, patients are at risk from severe infections even in the absence of neutropenia. This paper describes 3 patients with haemopoietic dysplasias in whom neutrophil microbicidal activity was deficient in vitro. The important abnormality appeared to be defective release of myeloperoxidase into the phagocytic vacuole. Two of these patients suffered from numerous baterial infections.
\end{abstract}

\section{Introduction}

Haemopoietic dysplasia is not a rare clinical problem; it has been said to occur with a frequency of $\mathbf{2}$ cases for every $\mathbf{5}$ of overt leukaemia (Linman and Bagby, 1976). Nevertheless, such cases are commonly a source of difficulty in diagnosis and management for the clinician, and result in extensive and unnecessary investigations for the patient. Some of this difficulty stems from the variety of names which are applied to the condition; pre-leukaemia, smouldering leukaemia, refractory anaemia with excess myeloblasts, and stem cell dysplasia are not the only examples.

The term haemopoietic dysplasia is used here to describe a chronic bone marrow disorder characterized by distinctive abnormalities in all myeloid compartments but without sufficient increase in blast cells for a diagnosis of acute leukaemia $(<10 \%)$. Symptoms and physical findings lack specificity, but haematological manifestations are remarkably constant. In a review of 132 cases Linman and Bagby (1976) found that males over 50 years were most commonly affected. They presented with the effects of peripheral blood cytopenias, most commonly pancytopenias $(44 \%)$. Erythropoiesis generally appears megaloblastic but serum $B_{12}$ and folate levels are not reduced, and multinucleated precursors with

Present address: Haematology Department, General Hospital, Nottingham. an excess of immature forms is common. Megakaryocytes are often increased in number despite thrombocytopenia, and atypical forms can be found. Changes in the granulocytic line may be subtle, consisting of monocytoid features, maturation defects and deficiencies in granulation. Myeloblasts are often not increased.

There are other associated abnormalities which can sometimes be detected in the absence of quantitative or morphological anomalies. These include: a decrease in blood group antigens, an increase or decrease in certain enzymic activities and an excess of haemoglobin F (Dacie et al., 1959), decreased neutrophil alkaline phosphatase (Dacie et al., 1959) reduced capacity of bone marrow cells to form granulocytic colonies in vitro (Editorial, 1973) chromosomal abnormalities (Rowley, Blaisdell anđ Jacobson, 1966), and platelet function abnormalities (Sultan and Caen, 1972).

The majority of these patients eventually develop acute leukaemia; in one study $71 \%$ in less than 2 years and the remaining $29 \%$ within 9 years (Linman and Bagby, 1976). A patient has been described in whom there was a pre-leukaemic phase of 20 years (Catovsky et al., 1971). Haemopoietic dysplasia can, however, be a cause of mortality in itself; and in a further series (Dreyfus, 1976) the cause of death in 102 patients was acute leukaemia in 28 , infection in the absence of leukaemia in 50, and unrelated causes in 24. Infection is a common, and often serious, problem which frequently occurs in the absence of neutropenia. Three patients with haemopoietic dysplasias in whom neutrophil function was assessed are now described.

\section{Patients}

\section{Case 1}

A 60-year-old clerical worker presented with general malaise of several months' duration. No specific abnormality was detected on examination but a full blood count revealed: haemoglobin $10 \cdot 2$ $\mathrm{g} / \mathrm{dl}$; MCV $80 \mathrm{fl}$; platelet count $119.0 \times 10^{9} / 1$; leucocyte count $3.2 \times 10^{\circ} / 1$ (neutrophils $22 \%$, eosinophils 
$3 \%$, lymphocytes $72 \%$, monocytes $3 \%$ ). Neutrophil alkaline phosphatase score was zero. Secondary granulation was absent from peripheral neutrophils on routine Romanowsky staining, as it was from granulopoietic cells in a bone-marrow aspirate. This specimen showed normal cellularity with a slight increase in blast cells $(8 \%)$. Chromosome analysis was not performed. Serum vitamin $\mathrm{B}_{12}$ and folate assays were normal.

He was not given specific therapy but required frequent red cell transfusions to maintain an adequate haemoglobin concentration. He was also troubled by frequent severe infections including staphylococcal and Pseudomonas septicaemia arising from blood transfusion drip sites, 2 episodes of acute cholecystitis, 5 episodes of pneumonia, and numerous pyrexias of uncertain aetiology. His blood picture remained unchanged for approximately 2 years until now (1978) when it is becoming more frankly leukaemic; platelet count $27.0 \times 10^{9} / 1$; leucocyte count $9.2 \times 10^{9} / 1$ (neutrophils $58 \%$, lymphocytes $17 \%$, monocytes $1 \%$, blasts $24 \%$ ). His bone marrow contains $36 \%$ blast cells.

\section{Case 2}

A 56-year-old former miner presented with a 2-month history of weakness, anorexia and weight loss. There were no relevant positive findings on physical examination. Full blood count showed: haemoglobin $11.8 \mathrm{~g} / \mathrm{dl}$; MCV $90 \mathrm{fl}$; platelet count $176.0 \times 10^{\%} / 1$; leucocyte count $34.2 \times 10^{9} / 1$ (neutrophils $78 \%$, lymphocytes $13 \%$, monocytes $2 \%$, myelocytes $7 \%$ ). Neutrophil alkaline phosphatase score was 70 . Bone marrow aspirated from the iliac crest was hypercellular with megaloblastoid erythropoiesis and an increase in granulopoietic activity, which showed a shift to the left including 3\% blast cells. Secondary granulation appeared deficient in all stages beyond the neutrophil myelocytes. Chromosome analysis of this sample demonstrated multiple abnormalities of number and structure varying between cells, with no chromosomally normal cells. Serum vitamin $B_{12}$ and folate assays were normal.

He was treated conservatively but over the next few months his general condition gradually deteriorated with profound weakness and recurrent chest and urinary tract infections. There was no significant change in his blood picture apart from a fall in haemoglobin concentration to $9 \cdot 2 \mathrm{~g} / \mathrm{dl}$. Bone marrow findings were unaltered 2 weeks before his death from cerebral haemorrhage 8 months after presentation. One further point of interest was the loss of B antigen from this patient's red cells which occurred between the time of presentation (complete macroscopic agglutination with anti-B) and retesting 7 months later (microscopic agglutination ++ only with anti-B).

\section{Case 3}

A 76-year-old retired clerk presented with a 6-month history of lethargy, intermittent itching and excessive bruising. On examination the spleen was palpable $4 \mathrm{~cm}$ below the left costal margin. Full blood count showed: haemoglobin $9.7 \mathrm{~g} / \mathrm{dl}$; MCV $119 \mathrm{ff}$; platelet count $70.0 \times 10^{\%} / 1$; leucocyte count $30.3 \times 10^{9} / 1$ (neutrophils $71 \%$, eosinophils $10 \%$, lymphocytes $15 \%$, monocytes $2 \%$, myelocytes $2 \%$ ). Neutrophil alkaline phosphatase score was 200 . Bone marrow aspirated from the iliac crest was hypercellular with megaloblastoid erythropoiesis and an increase in granulopoietic activity without a relative increase in promyelocytes and blasts. Secondary granulation in the neutrophil series was deficient and Pelger forms prominent. Chromosomal analysis of this sample revealed 2 populations of cells; one with $46 \mathrm{XY}$ constitution and one with $47 X Y+C$ (8 or 10 ). Serum vitamin $B_{12}$ and folate analysis were normal.

He was not given specific therapy but over the next 11 months required repeated red cell transfusions. Otherwise he remained relatively well apart from occasional epistaxis, and was not troubled by infection. Full blood counts demonstrated a rising white count and falling platelet count. He died from cerebral haemorrhage 11 months after presentation with haemoglobin $7.8 \mathrm{~g} / \mathrm{dl}$; platelet count $21.0 \times 10^{9} / 1$; leucocyte count $69.0 \times 10^{9} / 1$ (neutrophils $72 \%$, eosinophils $2 \%$, lymphocytes $9 \%$, monocytes $2 \%$, myelocytes $8 \%$, blasts $9 \%$ ).

\section{Materials and methods}

Neutrophil function was assessed on the basis of the ability of these cells to phagocytose and kill a species of Candida (C. guilliermondi). The method was described by El-Maalem and Fletcher (1976). Essentially, peripheral blood neutrophils at a concentration of $9 \times 10^{6} / \mathrm{ml}$ are incubated with an equal volume of Candida at a concentration of $4 \times 10^{7}$ organisms $/ \mathrm{ml}$ in ${ }^{199} \mathrm{TC}$ at $37^{\circ} \mathrm{C}$. The mixture is sampled at 15 and $90 \mathrm{~min}$, and slides prepared with a cytocentrifuge. The preparations are then stained with Leishman and for myeloperoxidase (Kaplow, 1965). At $91 \mathrm{~min}$ the mixture is sonicated for $10 \mathrm{~s}$ to disrupt leukocytes without affecting Candida. Cytocentrifuge preparations are stained with Leishman.

Phagocytosis is assessed at $15 \mathrm{~min}$ and 2 separate measurements can be made; the proportion of neutrophils that has engulfed Candida (percentage phagocytosis) and the proportion of Candida that has been engulfed (percentage uptake). Initial myeloperoxidase content is also assessed on this 
sample and compared with that of the neutrophils in the 90-min sample. Candida killing is assessed from sonicated preparation by the percentage of pale pink degraded organisms compared with the dark blue living organisms on the Leishman stain.

\section{Results}

Neutrophil function tests as described were performed on peripheral blood from the 3 patients and from 3 healthy volunteers. Results are shown in Table 1.

Although patients' neutrophils appeared to phagocytose Candida normally within $15 \mathrm{~min}$ there was a significant difference $(P<0.01)$ between killing of organisms by the patients' and controls' neutrophils after $90 \mathrm{~min}$. There was no difference in myeloperoxidase content of the neutrophils of the 2 groups at $15 \mathrm{~min}$ as judged by visual assessment of the stain reaction product. All cells were uniformly strongly positive. However, when samples were stained for myeloperoxidase after $90 \mathrm{~min}$ the normal neutrophils demonstrated considerable loss of this staining property, whereas the test neutrophils still showed heavy staining not obviously different from that in the 15-min specimen. From these observations it was concluded that there was failure of the normal release of myeloperoxidase into the phagocytic vacuole of these patients' neutrophils wth consequent reduction of microbial killing.

Peripheral blood neutrophils were also scored for alkaline phosphatase (Dacie and Lewis, 1975). Patients 1,2 and 3 score 0,70 and 200 respectively compared with 52, 64 and 78 for 3 controls.

\section{Discussion}

Many patients with haemopoietic dysplasias develop severe or lethal infections in the absence of blastic proliferation, and these patients often possess normal numbers of neutrophils (Dreyfus, 1973). There have been several previous reports of defective function of these neutrophils in vitro. Ruutu et al. (1977) detected a cellular defect in chemotaxis in three patients, but the majority of these reports
(Lehrer et al., 1972; Breton-Gorius, Houssay and Dreyfus, 1975a,b; Davis, Brunning and Quinn, 1971) have shown a marked deficiency of myeloperoxidase as the cause of impaired bactericidal activity. One report (Breton-Gorius et al., 1975b) however, did describe a patient with variation in the myeloperoxidase content of the azurophilic granules of his peripheral blood neutrophils. In those neutrophils which contained the enzyme the granules appeared not to fuse with the phagocytic vacuole.

In each of the 3 patients in the present study the myeloperoxidase content of the azurophils was comparable to that of normal controls, and the reason for impaired microbiocidal activity appeared to be defective degranulation. This is similar to the results observed, using the same system, for the neutrophils of patients with chronic granulocytic leukaemia (El-Maalem and Fletcher, 1976). Factors controlling degranulation and the role of alkaline phosphatase in neutrophil function are poorly understood. Alkaline phosphatase was apparently normal in the neutrophils of case 2 and high in those of case 3 and so the defects described were not simply due to deficiency of this enzyme.

Clearly, the mechanism for defective function in the neutrophils of patients with haemopoietic dysplasia can vary. Whatever the basic abnormality these defects are of clinical significance. Infection has been reported as the initial manifestation in $15 \%$ of these patients (Saarni and Linman, 1973), and the cause of death, in the absence of acute leukaemia, in almost 50\% (Dreyfus, 1976). As already stressed, these patients are often not neutropenic. Two of the 3 above patients had severe infective problems, and the peripheral blood of case 2 always showed increased numbers of neutrophils.

The most important point in the management of these patients is the achievement of an early firm diagnosis, based on the criteria already discussed. The patient is then spared from lengthy, expensive and often frightening investigation, which unfortunately they have often to endure. Simple light microscopy of blood and bone marrow is the most

TABLE 1. Results of neutrophil function tests on patients and normal controls

\begin{tabular}{|c|c|c|c|c|c|}
\hline & \multirow{2}{*}{$\begin{array}{c}\text { Uptake } \\
(\%)\end{array}$} & \multirow{2}{*}{$\begin{array}{c}\text { Phagocytosis } \\
(\%)\end{array}$} & \multirow{2}{*}{$\begin{array}{c}\text { Killing } \\
(\%)\end{array}$} & \multicolumn{2}{|c|}{ Myeloperoxidase } \\
\hline & & & & $15 \mathrm{~min}$ & $90 \mathrm{~min}$ \\
\hline $\begin{array}{l}\text { Control } 1 \\
\text { Control } 2 \\
\text { Control } 3 \\
\text { Patient } 1 \\
\text { Patient } 2 \\
\text { Patient } 3\end{array}$ & $\begin{array}{l}52 \\
48 \\
56 \\
49 \\
51 \\
46\end{array}$ & $\begin{array}{l}74 \\
71 \\
78 \\
72 \\
73 \\
69\end{array}$ & $\begin{array}{l}45 \\
43 \\
46 \\
25 \\
21 \\
16\end{array}$ & $\begin{array}{l}+++ \\
+++ \\
+++ \\
+++ \\
+++ \\
+++\end{array}$ & $\begin{array}{r}+ \\
+ \\
+ \\
+++ \\
+++ \\
+++\end{array}$ \\
\hline
\end{tabular}

$++=$ Heavy stain throughout. $+=$ Light staining. 
essential part of diagnosis, and more specialized techniques such as chromosome analysis, neutrophil function studies and in vitro marrow culture usually provide confirmatory evidence.

It is now generally agreed that management should be conservative with close observation and specific treatment of clinically significant or life-threatening manifestations such as severe anaemia or infections if they occur. There is an isolated report of complete remission with cytotoxic drugs (Linman and Bagby, 1976), but in view of present inability to predict the time when evolution to full blown leukaemia may occur (up to 20 years), these are usually reserved until the marrow becomes packed with blast cells.

\section{Acknowledgments}

I thank Dr J. Fletcher for permission to study patients under his care, Dr H. El-Maalem for advice on neutrophil function tests, and Mrs Wendy McGuinness for typing this manuscript.

\section{References}

Breton-Gorius, J., Houssay, D. \& Dreyfus, B. (1975a) Partial myeloperoxidase deficiency in a case of preleukaemia 1. British Journal of Haematology, 30, 273.

Breton-Gorius, J., Houssay, D. \& Dreyfus, B. (1975b) Partial myeloperoxidase deficiency in a case of preleukaemia 2. British Journal of Haematology, 30, 279.

Catovsky, D., Shaw, M.T., Hoffbrand, A.V.\& Dacie, J.V. (1971) Sideroblastic anaemia and its association with leukaemia and myelomatosis: a report of five cases. British Journal of Haematology, 20, 385.

DACie, J.V., Smith, M.D., White, J.C. \& Mollin, D.L. (1959) Refractory normoblastic anaemia. A clinical study of seven cases. British Journal of Haematology, 5, 56.
Dacie, J.V. \& Lewis, S.M. (1975) Practical Haematology, 5th edn, p. 121. Churchill, London.

Davis, A.T., Brunning, R.D. \& Quinn, P.G. (1971) Polymorphonuclear leucocyte myeloperoxidase deficiency in a patient with myelomonocytic leukemia. New England Journal of Medicine, 285, 789.

Dreyfus. B., et al. (1969) Anomalies of blood group antigens and erythrocyte enzymes in two types of chronic refractory anaemia. British Journal of Haematology, 16, 303.

Dreyfus, B. (1973) Granulocytopathies acquises au cours des leucémies et des anémies réfractaires. Nouvelle Revue Française d'Hématologie, 13, 243.

Dreyfus, B. (1976) Preleukemic states. Nouvelle Revue Française d'Hématologie, 17, 33.

Edtorial (1973) Preleukemia. Lancet, i, 1426.

El-MaAlem, H. \& Fletcher, J. (1976) Defective neutrophil function in chronic granulocytic leukaemia. British Journal of Haematology, 34, 95.

KAPLOw, L.S. (1965) Simplified myeloperoxidase stain using benzidine dihydrochloride. Blood, 26, 215.

Lehrer, R.I., Goldberg, L.S., APPle, M.A. \& RosenPhal N.P. (1972) Refractory megaloblastic anemia with myeloperoxidase deficient neutrophils. Annals of Internal Medicine, 76, 447.

Linman, J.W. \& BAGBY, G.C. (1976). The preleukemic syndrome: clinical and laboratory features, natural course, and management. Nouvelle Revue Française d'Hématologie, 16, 11.

Rowley, J.D., Blaisdell, R.K. \& Jacobson, L.O. (1966) Chromosome studies in preleukemia. Blood, 27, 782.

RuUTu, P., et al. (1977) Function of neutrophils in preleukemia. Scandinavian Journal of Haematology, 18, 317.

SAarni, M.I. \& Linman, J.W. (1973). Preleukemia. The hematologic syndrome preceding acute leukemia. American Journal of Medicine, 55, 38.

Sultan, Y. \& CaEN, J.P. (1972) Platelet dysfunction in preleukemic states and in various types of leukemia. Annals of the New York Academy of Sciences, 201, 300. 